\title{
Low level methylmercury exposure affects neuropsychological function in adults
}

\author{
Edna M Yokoo ${ }^{1}$, Joaquim G Valente², Lynn Grattan³ ${ }^{3}$, Sérgio Luís Schmidt ${ }^{4}$, \\ Illeane Platt ${ }^{3}$ and Ellen K Silbergeld ${ }^{* 5}$
}

\begin{abstract}
Address: ${ }^{1}$ Institute of Social Medicine-Universidade Estaduel do Rio de Janeiro, and Institute of Collective Health-Universidade Federal de Mato Grosso Cuiiaba [MG] Brazil, 2Institute of Social Medicine-Universidade Estaduel do Rio de Janeiro, and National School of Public Health FIOCRUZ Rio de Janeiro [RJ] Brazil, ${ }^{3}$ Department of Neurology University of Maryland School of Medicine Baltimore MD 21202, USA, ${ }^{4}$ Department of Neurophysiology Universidade Estadual do Rio de Janeiro Rio de Janeiro [RJ] Brazil and ${ }^{5}$ Department of Environmental Health Sciences Johns Hopkins University Bloomberg School of Public Health Baltimore MD 21205 USA
\end{abstract}

Email: Edna M Yokoo - eyokoo@terra.com.br; Joaquim G Valente - valente@ensp.fiocruz.br; Lynn Grattan - lgrattan@medicine.umaryland.edu; Sérgio Luís Schmidt - valente@ensp.fiocruz.br; Illeane Platt - lgrattan@medicine.umaryland.edu; Ellen K Silbergeld* - esilberg@jhsph.edu

* Corresponding author

Published: 4 June 2003

Environmental Health: A Global Access Science Source 2003, 2:8

This article is available from: http://www.ehjournal.net/content/2/I/8

(c) 2003 Yokoo et al; licensee BioMed Central Ltd. This is an Open Access article: verbatim copying and redistribution of this article are permitted in all media for any purpose, provided this notice is preserved along with the article's original URL.

Received: 20 February 2003

Accepted: 4 June 2003

\begin{abstract}
Background: The neurotoxic effects of methylmercury $(\mathrm{MeHg})$ have been demonstrated in both human and animal studies. Both adult and fetal brains are susceptible to the effects of $\mathrm{MeHg}$ toxicity. However, the specific effects of adult exposures have been less well-documented than those of children with prenatal exposures. This is largely because few studies of $\mathrm{MeHg}$ exposures in adults have used sensitive neurological endpoints. The present study reports on the results of neuropsychological testing and hair mercury concentrations in adults (>17 yrs) living in fishing communities of Baixada Cuiabana (Mato Grosso) in the Pantanal region of Brazil.
\end{abstract}

Methods: A cross-sectional study was conducted in six villages on the Cuiaba River. Participants included 129 men and women older than 17 years of age. They were randomly selected in proportion to the age range and number of inhabitants in each village. Questionnaire information was collected on demographic variables, including education, occupation, and residence history. Mercury exposure was determined by analysis of hair using flameless atomic absorption spectrophotometry. The neurocognitive screening battery included tests from the Wechsler Memory Scale and the Wechsler Adult Intelligence Scale, Concentrated Attention Test of the Toulouse-Pierron Factorial Battery, the Manual Ability Subtests of the Tests of Mechanical Ability, and the Profile of Mood States.

Results: Mercury exposures in this population were associated with fish consumption. The hair mercury concentration in the 129 subjects ranged from 0.56 to $13.6 \mu \mathrm{g} / \mathrm{g}$; the mean concentration was $4.2 \pm 2.4$ micrograms/g and the median was $3.7 \mu \mathrm{g} / \mathrm{g}$. Hair mercury levels were associated with detectable alterations in performance on tests of fine motor speed and dexterity, and concentration. Some aspects of verbal learning and memory were also disrupted by mercury exposure. The magnitude of the effects increased with hair mercury concentration, consistent with a dose-dependent effect.

Conclusions: This study suggests that adults exposed to $\mathrm{MeHg}$ may be at risk for deficits in neurocognitive function. The functions disrupted in adults, namely attention, fine-motor function 

exposures.

\section{Background}

In recent years there has been a growing appreciation for acquired risk factors for neurologic disease and neuropsychological dysfunction, including exposures to environmental neurotoxicants such as the heavy metals. In this investigation, we studied the effects of environmental exposures to methylmercury ( $\mathrm{MeHg}$ ) via diet on neurocognitive status in adults. This study is of critical importance as worldwide concerns have focused on $\mathrm{MeHg}$ exposures. In many regions of the world, elemental mercury is used in small scale gold mining and MeHg is a byproduct of the contamination of aquatic systems by these mining processes [1]. Worldwide, adults as well as children are exposed to $\mathrm{MeHg}$ through the diet $[2,3]$.

An intensive gold rush began in the early 1980s in the Pantanal and Amazon Regions of Brazil [4]. Although declines in global prices for gold have led to decreased mining in recent years, previous mining activity continues to have consequences for the environment and its inhabitants. Small scale or informal gold mining, known in Portuguese as garimpagem, has significantly increased environmental mercury levels in water, sediments, and fish [5]. In this process, metallic mercury $\left(\mathrm{Hg}^{0}\right)$ is used to recover particulate gold from alluvial deposits by crude amalgamation [6,7]. During amalgamation and crude refining, significant amounts of $\mathrm{Hg}^{0}$ are discharged into the surrounding water, soil and air [5-8]. In aquatic systems inorganic mercury is converted to $\mathrm{MeHg}$ by bacteria in sediments, bioaccumulated in fish and biomagnified through the aquatic food chain [3].

The neurotoxic effects of $\mathrm{MeHg}$ especially during intrauterine development, have been demonstrated in both human and animal studies [3,10]. MeHg exposure is associated with a wide range of central nervous system dysfunctions in both children and adults [11]. Recent studies suggest an increased susceptibility of the developing nervous system to low level exposures, particularly during prenatal development [[12-14], reviewed by [7]]. Neuropsychological data from most of these studies indicate that children exposed during prenatal development performed more poorly on several neuropsychological measures including concentration, fine motor speed, and verbal memory than non-exposed children (but see ref [15]]. However the specific effects of environmental $\mathrm{MeHg}$ exposures in adults are less well characterized.

In adults, MeHg exposure is thought to cause selective damage relatively restricted to the granule cells of the cer- ebellum and neurons in the visual cortex $[11,16]$. In studies at Minamata, Japan, where the population consumed MeHg contaminated fish, high levels of prenatal exposure caused diffuse cerebral and cerebellar damage in infants and children. In contrast, the relatively few adults studied postmortem had more restricted and focal cerebral lesions [17]. The most common clinical signs observed in adults in the Minamata episode were paresthesia, ataxia, gait disturbance, sensory disturbances, tremors, visual and hearing impairments [18]. Formal neuropsychological assessments in adults were not reported. In 1971, a number of people in Iraq were exposed to organomercury-treated seed grain that was used mistakenly to make bread [19]. The predominant symptom noted in adults was paresthesia, which typically emerged after a latent period of 16 to 38 days [11]. The most severely affected individuals presented with ataxia, blurred vision, slurred speech and hearing difficulties $[10,11]$. Standardized neuropsychological assessments were not conducted. Based upon these events and other data from occupational studies, the World Health Organization proposed that limiting exposure to a maximum hair mercury concentration of 50 to $125 \mu \mathrm{g} / \mathrm{g}$ would prevent paresthesia [9]. The International Programme on Chemical Safety maintained this recommendation in its criteria document published in $1990[20]$.

However, these recommendations are based upon very high exposure episodes that resulted in hair mercury concentrations in the range of hundreds of micrograms per gram [2]. A critical contemporary issue in environmental health is the determination of the level at which MeHg is toxic in persons with chronic low level exposure, which primarily results from consumption of contaminated fish [21]. Recent studies of chronic low level MeHg exposures in adults suggest that a guidance level of $50 \mu \mathrm{g} / \mathrm{g}$ in hair may not be protective. Specifically, hair mercury concentrations below $50 \mu \mathrm{g} / \mathrm{g}$ have been associated with neurobehavioral disturbances in aspects of visual (chromatic discrimination, contrast sensitivity and peripheral fields) and psychomotor functions (tremor, dexterity, grip strength, complex movement sequences, hand-eye coordination, and rapid alternating movement) [6,22-26]. Further studies are needed to delineate the potential neurocognitive effects associated with low level $\mathrm{MeHg}$ exposure for adults, in order to provide a rational basis for safety levels.

To this end, we evaluated the neurocognitive status of riverine populations in the Pantanal region of Brazil. These 
communities are dependent upon fish as a main source of food and protein $[27,28]$. As a result of decades of small scale gold mining and deforestation in this region, as well as in Amazonia, many aquatic systems are contaminated with mercury and many fish species contain relatively high levels of mercury [28-32]. The results presented in this paper are part of a larger regional project on "Mercury Contamination Risks Via Food Chain in Baixada Cuiabana, Pantanal - Brazil". In this project, mercury levels have been measured in humans (blood, urine, hair), fish, water, and sediments. Levels of MeHg in humans have been studied with respect to diet, fish consumption, sociodemographic information, self-reported symptoms and morbidity, and neurological and neurocognitive status [27]. Fish consumed in this region contain a mean of 0.7 $\mu \mathrm{g} / \mathrm{g}$ in the edible portion of carnivorous species, or 0.08 $\mu \mathrm{g} / \mathrm{g}$ in herbivorous species [27]. The substantial amount of data available on these exposures makes this a useful context for epidemiologic research.

\section{Methods}

\section{Population and sampling}

The sample for this study was drawn from residents living in the 6 largest fishing villages along the Cuiabá River, between the municipalities of Santo Antônio do Leverger and Barão de Melgaço in Baixada Cuiabana, Pantanal region - Brazil. This region is part of the Pantanal flood plain ecosystem in the southern region of Mato Grosso State. It is bordered by the tropical rain forest of the Amazon in the north and by the dry bush land savannah to the northeast. The studied area is approximately $250 \mathrm{~km}$ downstream from Poconé, an important gold mining area in Pantanal that was active in the early 1980s. According to data from the state of Mato Grosso, the annual gold production in this region in 1985 was 2.12 tons, which is estimated to involve the use of about 1 ton of mercury for amalgamation [5]. Studies on exposures of gold miners and gold processors in the region have demonstrated substantial exposures to mercury as well as releases to the environment $[29,33,34]$.

This study was based upon a census conducted along the Cuiabá River in 1995 [27,35,36]. The total population in the geographic region of interest was 1,387. The six largest villages had a total of 1,159 inhabitants, representing $83 \%$ of the population. Using a maximum sampling error of $10 \%$ and a confidence interval of $95 \%$, individuals were selected randomly and proportionally to the number of inhabitants in these six villages as well as proportionally by age groups ( 6 to 14,15 to 49 , and above 50 years of age). The population sample from each village was also similar in terms of educational attainment and dietary patterns $[35,36]$. Persons were excluded if they had lived in the study area for less than 6 months or reported having worked in gold mining or in gold trading shops. These exclusions were established in order to include persons with at least semi-chronic exposures (although this may have excluded persons with an interruption in earlier exposures), and to exclude persons with occupational exposures to inorganic mercury compounds. For this study, 160 persons 17 years or older were selected from a total of 240 whose mercury exposures were assessed. This age cut-off conforms to requirements for ethical conduct of research in Brazil; inclusion of subjects $<17$ years requires special approval for research on children. Neuropsychological data are reported in this study for these adult men and women. All participants gave informed consent to the study, which was approved by the institutional review board of the Universidade Federal de Mato Grosso.

\section{Mercury exposure assessment}

Hair mercury levels were utilized as a biomarker of chronic exposure, since hair analysis is generally used in assessing environmental exposures to $\mathrm{MeHg}$ $[3,7,10,11,37]$. From each subject, a hair sample of approximately $2 \mathrm{~cm}$ was taken near the root just above the neck. Thus, hair mercury levels in this study represented relatively recent exposure, over the past 1-3 months [11]. The hair was washed and stored in sealed plastic bags prior to measurement. Total mercury content in hair was determined by acid digestion and atomic absorption spectrophotometry, using standard methods, at the trace metal analysis laboratory of the Universidade Federal da Mato Grosso, which meets the QA/QC criteria (including regular tests using blinded duplicates and standards to test accuracy and sensitivity) of the Interlaboratory Comparison Program coordinated by the Centre de Toxicologie du Quebec, Canada. Because exposures in this population were largely, if not exclusively, to MeHg in fish, a determination of total mercury in hair was likely to be between 80 - 95\% MeHg [3,14,23,27].

\section{Neurobehavioral tests}

The participants were interviewed and tested by trained investigators. Neurocognitive testing was done over the same time period of the day (late morning to early afternoon). Four Brazilian psychologists, formally trained in the neurobehavioral procedures, administered and scored the measures. They were unaware of the participants' hair mercury concentrations (which were analyzed separately and after the testing of the subjects was completed in the field). The participants were administered neuropsychological measures as recommended for assessing occupational neurotoxicity by the Health Secretariat of Sao Paulo State in Brazil [38], which are similar to the recommendations of the World Health Organization [39]. These included the following measures: 
1. The Orientation, Mental Control, Logical Memory, Digit Span, Visual Reproduction and Paired Associate Learning tests from the Wechsler Memory Scale (Portuguese version) were administered and scored in standard fashion to assess attention, learning and memory [40].

2. The Digit Symbol Subtest of the Wechsler Adult Intelligence Scale (in Portuguese) was administered and scored according to standard procedures to assess sustained attention as well as clerical speed and accuracy [41].

3. The Manual Ability subtests of Leon Walter's Tests of Mechanical Ability (TAM, Testes de Aptidao Mecanica) were also administered. The subtests assess manual speed and dexterity and involve placing disks on spindles, bead threading and marking dots. The measures were administered and scored according to the TAM battery manual [42].

4. The Concentrated Attention Test of the Toulouse Pierron Factorial Battery was administered to assess graphomotor speed in the execution of simple visuospatial and attentional tasks. The measure was administered and scored according to the CEPA Battery manual. For data analysis, raw scores were used for total responses, total correct responses, total errors (errors of commission) and total omissions (errors of omission) [43].

In addition, the Profile of Mood States (POMS) was utilized as a general measure for assessing mood, anxiety and general distress. This test has been recommended for use in studies of occupational neurotoxicity in Brazil [38].

\section{Statistical analyses}

Descriptive statistics were used to characterize the studied population in terms of sociodemographic variables and hair mercury levels. Exposure was defined by hair mercury concentration. The relations between hair mercury and neurobehavioral function were first studied by correlation and partial correlations with three covariates in the analyses, age, sex and education level. Alcohol consumption was low in these populations, and not related to $\mathrm{MeHg}$ exposures. Because there were no significant differences in the major sociodemographic, dietary, occupational, or educational variables among the village populations, except for mercury exposures within each site [35], the population was analyzed as a whole. All correlations were Pearson's correlations and two sided tests were applied throughout. The associations between exposure and outcome variables were then analyzed by multiple regression with adjustment for relevant covariates. In addition to age, sex and educational level, additional covariates in these analyses were: alcohol intake, occupation and residence time, all of which were examined as covariates using stepwise methods. The regression equation model with overall test $F$ was considered statistically significant at $p \leq 0.05$. The regression model was also performed using a dichotomized stratification of exposure $<$ or $>6$ $\mu \mathrm{g} / \mathrm{g}$, based on the WHO hair mercury 'reference level' recommended for children and pregnant women exposed to $\mathrm{MeHg}$ since it is the only available international guideline for adult exposures within a range relevant to nonoccupational settings [20]. In addition, the results from each neurocognitive test were dichotomized by the median performance of the studied population in order to evaluate odds of poor performance. The relationships between outcomes and exposure, stratified by the median of each test and by exposure, were analyzed.

\section{Results}

Of the 160 adults recruited for this study, 150 agreed to participate. The 10 refusals did not differ from the participants in terms of age, education, gender, or diet. The main reason given for refusal was lack of time to participate. Of the 150 participants, data on mercury exposure by hair mercury analysis was available on 129, and these subjects provide the data discussed here. Because the hair analyses were done after enrollment and testing, the final number of subjects in this study differs from the number actually tested. The number of persons completing each test varied, and the main determinant of failure to complete a test was advanced age ( $>60$ years). No other single factor accounted for failure to complete the tests. The data reported in this study are for a group of 52 men and 77 women, with ages ranging from 17 to 81 years (mean: 35 \pm 15 ). Other relevant sociodemographic data are summarized in Table 1. Most women (90\%) reported being housewives; most men (67\%) were involved in fishing. The hair mercury concentration in the 129 subjects ranged from 0.56 to $13.6 \mu \mathrm{g} / \mathrm{g}$; the mean concentration was $4.2 \pm$ $2.4 \mu \mathrm{g} / \mathrm{g}$ and the median was $3.7 \mu \mathrm{g} / \mathrm{g}$, as shown in Fig 1 . Of these, fully $25 \%$ of the individuals had mercury concentration above the World Health Organization (WHO) "reference level" of $6 \mu \mathrm{g} / \mathrm{g}$ [20]. The general health of the population was good, with no obvious malnutrition or low body mass. In a separate study of diet and nutrition [36], the composition of the diet was measured by self report over 3 days. In general the diet was somewhat hypocaloric and low in carbohydrates, with normal lipid intake and high protein intake $[35,36]$.

\section{Neurobehavioral Tests}

Table 2 shows correlations and partial correlations of neuropsychological scores related to hair $\mathrm{Hg}$ concentration. There were significant relationships between hair mercury and the Bead Threading, Digit Span, Digit Symbol, Paired Associated Learning Test and measures of Logical Memory. A significant relationship was also found between hair $\mathrm{Hg}$ concentration and errors of commission on the 


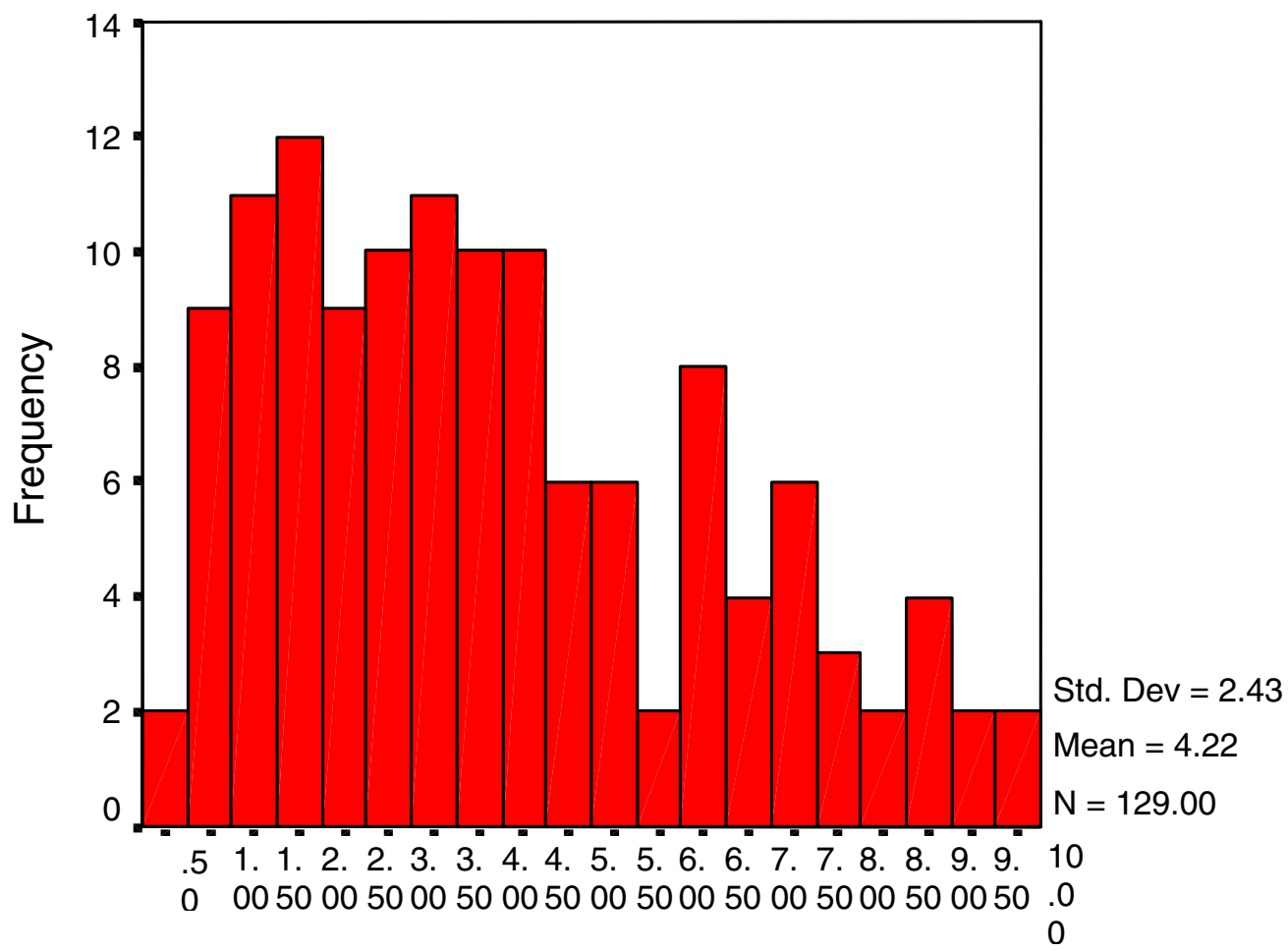

Hair mercury concentration (ppm)

Figure I
Distribution of hair mercury levels among participants $(n=129)$

Toulouse-Pierron test. No relationship was observed between hair $\mathrm{Hg}$ and any measure on the POMS.

For each test, partial correlations were adjusted, using multiple regression analysis, for the following potential confounding variables: sex, age, educational level, smoking, alcohol intake. Sex was reported as a dichotomous variable; age was reported in years. Dummy variables were used for the following: educational level, which was reported as illiterate, first or primary level education, second or intermediate level education, third or more than intermediate; smoking, which was reported as never, former, or current; alcohol intake, which was reported as none, once a week, 2-3 times per week, and as drinks per day ( 1 or 2-4 glasses per day, 1 bottle or $>1$ bottle per day). These variables were selected because they are known to affect performance on these tests and because in these data they significantly affected the overall relation between mercury and test performance. No other variables entered significantly into the model. After adjustment only the correlations between Digit Symboltest results and hair Hg were no longer observed.

According to the $\beta$ coefficients and 95\% confidence intervals in the multiple regression analyses, increasing hair $\mathrm{Hg}$ concentration was associated with worse scores on the following tests: bead threading, Digit Span (total score and number of digits accurately recalled in reverse order), Digit Symbol, Logical Memory and the Paired Associative Learning Test (easy and hard word pairs) and errors of commission on the Toulouse-Pierron Test. After adjusting for age, gender, and educational level, bead threading and errors of commission scores showed higher coefficients. Confidence intervals for Digit Symbol and learning difficult word pairs included zero (Table 3 ). 
Table I: Demographic characteristics of the study population.

\begin{tabular}{|c|c|c|}
\hline Characteristic & $\mathbf{N}$ & Percentage \\
\hline \multicolumn{3}{|l|}{ Gender } \\
\hline Women & 77 & 60.0 \\
\hline Men & 52 & 40.0 \\
\hline \multicolumn{3}{|l|}{ Age (years) } \\
\hline $17-24$ & 40 & 31.0 \\
\hline $25-34$ & 32 & 24.8 \\
\hline $35-44$ & 30 & 23.3 \\
\hline $45-54$ & 10 & 7.7 \\
\hline $55-64$ & 07 & 5.5 \\
\hline$\geq 65$ & 10 & 7.7 \\
\hline \multicolumn{3}{|l|}{ Education level } \\
\hline Illiterate or write name & 33 & 25.6 \\
\hline Basic primary & 82 & 63.6 \\
\hline Uncomp. Ist grade & 09 & 7.0 \\
\hline Comp. | st grade $^{\text {st }}$ & 03 & 2.2 \\
\hline Uncomp. $2^{\text {nd }}$ grade & 02 & 1.6 \\
\hline \multicolumn{3}{|l|}{ Smoking habits } \\
\hline Nonsmoker & 97 & 75.0 \\
\hline Smoker & 32 & 25.0 \\
\hline \multicolumn{3}{|l|}{ Alcohol intake } \\
\hline Nondrinker & 103 & 80.0 \\
\hline Drinker & 26 & 20.0 \\
\hline \multicolumn{3}{|l|}{ Occupation } \\
\hline Fishing & II & 9.3 \\
\hline Fishing + other & 24 & 20.0 \\
\hline Agriculture & 12 & 10.0 \\
\hline Housewife & 69 & 40.0 \\
\hline Others & 13 & 20.7 \\
\hline \multicolumn{3}{|l|}{ Residence time (years) } \\
\hline$<5$ & 08 & 6.2 \\
\hline $5 \geq 20$ & 37 & 28.7 \\
\hline $20 \geq 35$ & 43 & 33.3 \\
\hline $35 \geq 50$ & 23 & 17.8 \\
\hline$\geq 50$ & 18 & 14.0 \\
\hline
\end{tabular}

The multiple regression coefficients, using hair mercury dichotomized on the basis of the WHO criteria, are presented in Table 4. The Bead Threading, Digit Symbol and errors of commission of the Toulouse-Pierron Test predicted group membership (that is, persons with hair $\mathrm{Hg}$ levels above or below $6 \mu \mathrm{g} / \mathrm{g}$ ) with higher coefficients than when $\mathrm{Hg}$ exposure was considered as a continuous variable. This finding was maintained when scores were adjusted for age, gender and education.

Table 5 presents neuropsychological test data dichotomized by a median split for each test. Significant associations were observed between hair mercury and less than median performance on Bead Threading, Digit Span Backward, Digit Symbol, easy word pair learning, logical memory, and errors commissions on the ToulousePierron Test ( $p$ value $\leq 0.05$ ). These stratified relationships are reported as odds ratios in Table 6 . The odds of a neu- ropsychological score below the median in the population was higher for hair mercury concentrations above 6 $\mu \mathrm{g} / \mathrm{g}$ for Bead Threading ( $\mathrm{OR}=3.5$ ), and Paired Associative Learning $(\mathrm{OR}=2.9)$.

\section{Discussion}

The results of this study indicate that adults exposed to $\mathrm{MeHg}$ through fish consumption may have observable deficits in neurobehavioral performance measures, without detectable alterations in mood or affect. Since this is a cross sectional study, it is not possible to determine the extent to which these effects were associated with current exposures, as measured by analysis of $\mathrm{Hg}$ in hair at the scalp, with prior exposures earlier in life (particularly in utero), or both. However, prior exposures were not likely to wholly explain the results of this study of adults. First, length of residence in the region was not significantly associated with either hair mercury level or outcome. Sec- 
Table 2: Pearson correlation (R) of adults' hair mercury concentration and neurobehavioral test results.

\begin{tabular}{|c|c|c|c|c|c|}
\hline Test & $\mathbf{N}$ & $\mathbf{R}^{\mathbf{a}}$ & $P$ value & $\mathbf{R}^{\mathbf{b}}$ & $P$ value \\
\hline \multicolumn{6}{|l|}{ TAM } \\
\hline Manual Dexterity & 107 & -0.02 & 0.79 & -0.007 & 0.94 \\
\hline Fine Motor Speed & 113 & -0.26 & $0.006 *$ & -0.27 & $0.005^{*}$ \\
\hline \multicolumn{6}{|l|}{ WMS } \\
\hline Information & 129 & -0.08 & 0.35 & -0.10 & 0.28 \\
\hline Orientation & 129 & -0.01 & 0.93 & -0.014 & 0.88 \\
\hline Mental Control & 129 & -0.12 & 0.16 & -0.10 & 0.29 \\
\hline Logical Memory & 129 & -0.03 & 0.69 & 0.03 & 0.75 \\
\hline $\begin{array}{l}\text { Logical Memory } \\
\text { first story }\end{array}$ & 119 & -0.25 & $0.005^{*}$ & -0.23 & $0.014^{*}$ \\
\hline $\begin{array}{l}\text { Logical Memory } \\
\text { second story }\end{array}$ & 121 & -0.15 & 0.10 & -0.14 & 0.13 \\
\hline Digit Span & 128 & -0.20 & $0.046^{*}$ & -0.20 & $0.05^{*}$ \\
\hline Digit Span forward & 129 & -0.13 & 0.15 & -0.11 & 0.22 \\
\hline $\begin{array}{l}\text { Digit Span } \\
\text { backward }\end{array}$ & 129 & -0.20 & $0.05^{*}$ & -0.20 & $0.03 *$ \\
\hline $\begin{array}{l}\text { Visual } \\
\text { Reproduction }\end{array}$ & 129 & -0.10 & 0.29 & -0.06 & 0.56 \\
\hline $\begin{array}{l}\text { Associative } \\
\text { Learning }\end{array}$ & 129 & -0.15 & 0.08 & -0.15 & 0.12 \\
\hline Easy learning & 129 & -0.20 & $0.03 *$ & -0.20 & $0.03 *$ \\
\hline Difficult learning & 128 & -0.18 & $0.04 *$ & -0.15 & 0.10 \\
\hline Memory Quotient & 128 & -0.09 & 0.30 & -0.13 & 0.17 \\
\hline \multicolumn{6}{|l|}{ WAIS } \\
\hline Digit Symbol & 122 & -0242 & $0.007^{*}$ & -0.14 & 0.13 \\
\hline \multicolumn{6}{|l|}{$\begin{array}{l}\text { Toulouse - Pierron } \\
\text { (CEPA) }\end{array}$} \\
\hline Total answers & 116 & -0.08 & 0.41 & -0.01 & 0.30 \\
\hline Correct answers & 116 & -0.07 & 0.45 & -0.01 & 0.30 \\
\hline $\begin{array}{l}\text { Errors - } \\
\text { commissions }\end{array}$ & 116 & 0.22 & $0.016 *$ & 0.23 & $0.015^{*}$ \\
\hline Errors - omissions & 116 & -0.16 & 0.08 & -0.12 & 0.20 \\
\hline \multicolumn{6}{|l|}{ POMS } \\
\hline Tension & 129 & -0.16 & 0.07 & 0.12 & 0.63 \\
\hline Anger & 129 & -0.08 & 0.37 & -0.21 & 0.39 \\
\hline Vigor & 129 & 0.04 & 0.64 & 0.07 & 0.76 \\
\hline Confusion & 129 & -0.02 & 0.83 & -0.12 & 0.61 \\
\hline Fatigue & 129 & -0.04 & 0.65 & -0.14 & 0.56 \\
\hline Depression & 129 & -0.01 & 0.96 & -0.15 & 0.53 \\
\hline
\end{tabular}

a bivariate correlations ${ }^{b}$ Partial correlations adjusted by age, sex and education level $* \mathrm{p}$ value $<=0.05$

ond, the major period of gold mining in this region began in the 1980s $[4,8,34]$, so that exposure to $\mathrm{MeHg}$ in fish, downstream from mining sites, was unlikely to have begun until some time after the mid 1980s, allowing for hydrologic dispersion of mercury and contamination of the aquatic food chain, at which point all of the persons in this cohort were already born. However, a longitudinal study is necessary to fully determine the role of timing of exposure in these observed outcomes.

The possibility of adverse effects in adults at lower levels of mercury exposure than those relied upon for occupational guidance has been raised by other studies in Brazil of fish-consuming populations [6,23-26]. Several of these studies have considered diet and nutrition as covariates $[23,24]$. The populations in this study are not undernourished or grossly deficient in nutrient intake. In general, health status is good to excellent, with the exception of risks of infection by endemic parasites and helminths $[36,45]$. Alcohol consumption was relatively low in this population, with $80 \%$ reporting no alcohol consumption and no subjects reporting heavy consumption. No subjects were excluded on the basis of alcohol consumption. Consideration of either infection or alcohol consumption did not alter the observed associations between mercury exposure and neuropsychological outcomes in this study. 
Table 3: Regression coefficients $\beta$ of adult's hair mercury concentration as a predictor of neurobehavioral test results.

\begin{tabular}{lcccc}
\hline Test & $\beta^{*}$ & $\mathbf{9 5 \%} \mathbf{C l}$ & $\beta^{* *}$ & $\mathbf{9 5 \%} \mathbf{C l}$ \\
\hline Fine Motor Speed & -3.40 & $-5.80 ;-1.00$ & -3.20 & $-5.40 ;-1.00$ \\
Digit Span & -0.14 & $-0.29 ;-0.001$ & -0.15 & $-0.29 ; 0.003$ \\
Digit Span backward & -0.09 & $-0.18 ;-0.001$ & -0.09 & $-0.19 ;-0.009$ \\
Digit Symbol & -1.21 & $-2.08 ;-0.33$ & -0.54 & $-1.2 ; 0.16$ \\
Easy Learning & -0.37 & $-0.70 ;-0.04$ & -0.34 & $-0.64 ;-0.04$ \\
Difficult Learning & -0.21 & $-0.42 ;-0.001$ & -0.15 & $-0.34 ; 0.03$ \\
Logical Memory first story & -0.29 & $-0.51 ;-0.09$ & -0.27 & $-0.49 ;-0.06$ \\
Errors of commission & 1.39 & $0.26 ; 2.5$ & 1.45 & $0.28 ; 2.6$ \\
\hline
\end{tabular}

* _ not adjusted; ** _ adjusted by age, gender and education level;

Table 4: Regression coefficients $\beta$ of adults hair mercury concentration stratified on the base of the WHO* "reference level" as a predictor of neurobehavioral test results in children.

\begin{tabular}{|c|c|c|c|c|}
\hline Test & $\beta^{\mathbf{a}}$ & $95 \% \mathrm{Cl}$ & $\beta^{\mathbf{b}}$ & $95 \% \mathrm{Cl}$ \\
\hline Fine Motor Speed & -19.0 & $-31.0 ;-6.7$ & -17.7 & $-29.4 ;-6.3$ \\
\hline Digit Symbol & -7.82 & $-12.4 ;-3.2$ & -4.28 & $-7.9 ;-0.48$ \\
\hline Errors of commission & 9.0 & $3.1 ; 14.9$ & 9.0 & $2.9 ; 15.1$ \\
\hline
\end{tabular}

$\mathrm{a}$ - not adjusted; b - adjusted by age, gender and education level; * $6 \mu \mathrm{g} / \mathrm{g}$ (WHO reference level)

The strongest effects of mercury on persons in this study were detected on tests of fine motor speed and dexterity (Bead Threading) and response inhibition (errors of commission or "false alarms" on the timed visual search and attention tasks). The size of the effects increased with hair mercury concentration, consistent with a dose-dependent effect. Based upon extant data [particularly as reported in [23], we anticipated that the neuropsychological effects of $\mathrm{Hg}$ exposure in adults would be in domains of attention and concentration, memory, and psychomotor speed and dexterity. Hence, these functions were the focus of our screening battery. Post-hoc analyses were performed on Digit Span and Paired Associative Learning measures for purposes of clarification and interpretation of our findings, as well as for hypothesis generation for future studies. Since the Digit Span subtest was correlated with hair $\mathrm{Hg}$, we conducted a post hoc analysis to determine if simple attention (as measured by Digits Forward] or more complex attention and concentration (Digits Reverse) explained the findings. Our post hoc analysis indicated that the test component requiring greater demands on the attentional system (Digits Reverse) probably explained the correlation. Since memory has been previously reported to be affected by mercury exposure, and since we found no correlation between hair $\mathrm{Hg}$ and the Associative Learning subtest of the WMS we conducted post-hoc analysis to determine in memory correlations were found with the harder word associations (Difficult Pairs). They were not, and in fact, correlations were observed between hair $\mathrm{Hg}$ and the easy associations. These results may therefore reflect other factors such as motivational issues in the population. Visuomotor disturbances have also been described in similar exposure situations $[6,25,26]$. Decrements in performance on the visually guided fine motor speed and dexterity task (Bead Threading) were also found, while gross motor functions (placing disks, marking dots) were unaffected. These results are consistent with earlier studies [[22], also reviewed by [44]], which have suggested that mercury disrupts the cerebellum (a brain region associated with accurately aimed and smoothly executed coordinated movement) [46].

Mercury exposure appears to be associated with increased responding, that is, both correct responses and commission errors. Errors of commission generally reflect disturbances in response inhibition or inhibitory control Possible disturbances in select aspects of memory were also observed (working memory, new learning), which is consistent with previously reported findings in workers exposed to mercury vapor [47]. Because of differences in exposure, it is difficult to compare these results with studies of adults chronically exposed to inorganic mercury in the workplace, who have demonstrated cognitive impairments, including deficits in attention and executive function, short term memory, visuospatial ability, and motor function $[16,47]$. 
Table 5: Mean of hair mercury concentration $(\mu \mathrm{g} / \mathrm{g})$ stratified by the median of each neuropsychological test.

\begin{tabular}{lccc}
\hline Tests & Median & Hair Hg & P value* \\
\hline Fine Motor Speed & $<30$ & 4.8 & 0.006 \\
Digit Symbol & $\geq 30$ & 3.6 & 4.8 \\
Logical Memory total & $<20$ & 3.8 & 0.03 \\
Digit Span backward & $\geq 20$ & 4.6 & 3.7 \\
& $<03$ & 4.7 & 0.05 \\
Easy Learning & $\geq 03$ & 3.6 & 0.007 \\
Logical Memory first story & $\geq 02$ & 4.7 & 0.02 \\
& $<14$ & 3.7 & 4.9 \\
\hline
\end{tabular}

$*$ T-test with $p$ value $\leq 0.05$

For most of the tests, the size of the effects $-\beta$ coefficient - for the whole population is relatively small. However, when the population is stratified on the basis of the WHO standard, a relatively large effect of mercury exposure is observed, similar to findings for the effects of lead in children [48]. Also, the risk of performing below the median on neuropsychological tests of fine motor speed, logical memory, and digit span (backward) is generally increased in persons with higher hair mercury. These stratified analyses were undertaken to further elucidate the potential public health importance of these relatively low levels of exposure to $\mathrm{MeHg}$ in adults. Testing associations between exposure and outcome as continuous variables provides more sensitive information on potential effects at low exposures, as demonstrated in the regression analyses, but these dichotomized analyses may be relevant to public health policy. Recent proposals for public health policy, such as advisory levels for fish consumption, have generally assumed that children are significantly more sensitive than adults to the neurotoxic effects of $\mathrm{MeHg}[2,3,20,49]$. However, this study suggests that adults may be as sensitive as children to MeHg. Although there are differences in the tests used, some of the tests that evaluated similar domains or function showed decreased performance in adults (our study) and children [12-14] related to attention, fine motor function and memory. Of course the neurotoxic effects of $\mathrm{MeHg}$ in children differ significantly from those in adults, because of the specific properties of $\mathrm{MeHg}$ as a neurodevelopmental toxicant $[3,10,49]$; we draw the comparison to note the importance of preventing MeHg exposures to adults as well as children.

This is the first study of adults exposed to low levels of $\mathrm{MeHg}$, using neuropsychological tests comparable in sensitivity to the methods used in the Faeroes and Seychelles studies. Usually, motor function and visual field are the primary outcomes evaluated in cases of adult exposure, often in occupational settings of much higher exposures to inorganic mercury compounds. As in similar research on other environmental neurotoxicants, it is important to distinguish individual risk from population risk. Decreases in mean scores may be too small to detect or to evaluate as to clinical significance for one individual, but they may be quite important when considered in terms of the impact on the population distribution of the affected function, as has been shown for lead [49]. If this is the case, then the public health impacts of $\mathrm{MeHg}$ exposure at levels often encountered by adults in North America [2] may be inducing adverse effects on neurobehavioral performance. Further studies are necessary in order to confirm these findings and to understand the mechanisms by which $\mathrm{MeHg}$ can affect central nervous system function in adults.

\section{Authors' contributions}

EMY carried out the field studies as part of her dissertation research for the PhD degree from the UERJ. She enrolled subjects, administered tests, collected hair samples, and participated in all steps of analysis and preparation of the ms. JGV served as EMY's thesis adviser, and guided her development of this project and her analyses of data. LG advised EMY, while a visiting fellow at the University of Maryland, in the appropriate analyses and interpretation of neurobehavioral test data. SLS advised the UFMG research group on the selection of neurobehavioral tests for application in this field study. IP assisted LG and EMY in data analyses. EKS served as EMY's research adviser during her fellowship in the US and took final responsibility for the writing and revision of this manuscript.

\section{Competing interests}

None declared. 
Table 6: Odds ratios (unadjusted and adjusted) between hair mercury concentration stratified on the base of the WHO "reference level" and neurocognitive tests stratified by the median of each test.

\begin{tabular}{lllll}
\hline Test & OR & $\mathbf{9 5 \%} \mathbf{C l}$ & OR* & $\mathbf{9 5 \%} \mathbf{C l}$ \\
\hline Fine Motor Speed & 3.3 & 1.38 .0 & 3.5 & 1.29 .3 \\
Digit Symbol & 2.4 & 1.15 .2 & 1.6 & 0.65 .0 \\
Logical Memory first story & 2.6 & 1.16 .0 & 2.3 & 1.05 .8 \\
Digit Span backward & 2.6 & 1.15 .6 & 2.3 & 1.16 .0 \\
Easy Learning & 2.9 & 1.36 .5 & 2.9 & 1.17 .3
\end{tabular}

*Adjusted by age, sex and educational level

\author{
Abbreviations \\ $\mathrm{Hg}$ - mercury \\ MeHg - methylmercury \\ WHO - World Health Organization \\ OR - odds ratio \\ TAM - Tests of Mechanical Ability \\ POMS - Profile of Mood States \\ CEPA - Centro de Psicologica Aplicada
}

\section{Acknowledgements}

We would like to thank all the researchers who have participated in the overall project, and all the community residents in Baixada Cuiabana for being so helpful with our work by doing the tests, providing information and biological samples. Also we are indebted to Dr. Christopher Loffredo, Georgetown University Medical School, for his comments and suggestions on statistical analyses. This project was carried out in the Department of Chemistry and Department of Collective Health of the Universidade Federal de Mato Grosso, Brazil, as part of a large study of mercury contamination risks associated with the aquatic food chain, Baixada Cuiabana,

Pantanal - Brazil. The study was supported by a research grant from the International Development Research Center of Canada. As a doctoral student, Dr Yokoo was also supported by a "sandwich" grant from the Universidade Estaduel de Rio de Janeiro. Support for this research was provided to EMY, JGV, and SLS by the Federal Government of Brazil (CNPq). Support for EKS was provided by a Fogarty Center grant from the (US) National Institutes of Health.

\section{References}

I. Castilhos ZC, Bidone ED and Lacerda LD: Increase of the background human exposure to mercury through fish consumption due to gold mining at the Tapajos River Region, Para State, Amazon Bull Environ Contam Toxicol 1998, 61:202-209.

2. Mahaffey KR and Mergler D: Blood levels of total and organic mercury in residents of the upper St Lawrence River basin, Quebec Environ Res 1997, 77: 104-I I4.

3. National Research Council: Toxicological effects of Methylmercury Washington, DC, National Academy Press 2000.

4. Cleary D: Anatomy of the Amazon Gold Rush London: Macmillan 1990.

5. Lodenius M and Malm O: Mercury in the Amazon Rev Environ Contam Toxicol 1998, 157:25-52.
6. Branches FP, Erickson TB, Ask SE and Hryhorczuk D: The price of gold: mercury exposure in the Amazon rainforest Clin Toxicol 1993, 31:295-306.

7. Cordier $S$ and Grasmick C: Etude de l'impregnation par le mercure dans la population guyanaise Res Nat Sante Publique 1994: III4.

8. Câmara $\vee$ and Corey G: Epidemiologia e meio ambiente: o caso dos garimpos de ouro no Brasil Ed. Centro Panamericano de Ecologia Humana e Saúde(ECO/OPS). México 1992.

9. World Health Organization.: Methylmercury Environmental Health Criteria 101. Geneva, World Health Organization 1990.

10. Brubacher TM, Rodier PM and Weiss B: Methylmercury developmental neurotoxicity: a comparison of effects in humans and animals Neurotoxicol Teratol 1990, 1 2:191-202.

II. Myers GH, Davidson PW, Cox C, Shamlaye C, Cernichiari E and Clarkson TW: Twenty-seven years studying the human neurotoxicity of methylmercury exposures Environ Res 2000, 83:275285.

12. Kjellstrom T, Kennedy P, Wallis S and Mantell C: Physical and mental development of children with prenatal exposure to mercury from fish Stockholm, National Swedish Environmental Protection Board Report 36421989.

13. Grandjean P, Weihe P, White RF, Debes F, Araki S, Yokoyama K, Murata K, Sorensen N, Dahl R and Jorgensen PJ: Cognitive deficit in 7-year-old children with prenatal exposure to methylmercury Neurotoxicology and Teratology 1997, 19:417-28.

14. Grandjean P, White RF, Nielsen A, Cleary D and Santos ECO: Methylmercury neurotoxicity in Amazonian children downstream from gold mining Environ Health Perspect 1999, I07:586-59I.

15. Myers G], Davidson PW, Cox C, Shamlaye CF, Tanner MA, Marsh DO, Cernichiari E, Lapham LW, Berlin M and Clarkson TW: Summary of the Seychelles child development study on the relationship of fetal methylmercury exposure to neurodevelopment Neurotoxicology 1995, 16:7| I-6.

16. Feldman RG: Neurologic manifestation of mercury intoxication Acta Neurologica Scandinavia 1982, 66(suppl 92):201-9.

17. Eto K: Pathology of Minimata disease Toxicol Pathol 1997, 25:6I423.

18. Ninomiya T, Ohmori H, Hashimoto K, Tsuruta $K$ and Ekino S: Expansion of methylmercury poisoning outside of Minimata Environ Res 1995, 70:47-50.

19. Choi BH, Lapham LW, Amin-Zaki L and Saleem T: Abnormal neuronal migration, deranged cerebral cortical organization, and diffuse white matter astrocytosis of human fetal brain: a major effect of methylmercury poisoning in utero J Neuropathol Exp Neurol 1978, 37:719-33.

20. World Health Organization: Methylmercury Geneva, World Health Organization 1990.

21. Mahaffey KR: Recent advances in recognition of low-level methylmercury poisoning Curr Opin Neurol 2000, 13:699-707.

22. Beuter A, Geoffrey A and Edwards R: Analysis of rapid alternating movements in Cree subjects exposed to methylmercury and in subjects with neurological deficits Environ Res 1999 , 80:64-79.

23. Lebel J, Mergler D, Lucotte M, Amorim M and Dolbec J: Neurotoxic effects of low-level methylmercury contamination in the Amazonian Basin Environ Res 1998, 79(sec.A):20-31. 
24. Santos E, Loureiro ECB and de Jesus IM: Diagnosis of health conditions in a pan-mining community in the Tapajos River Basin, Itaituba, Para, Brazil, 1992 Cad Saude Publ 1995, I I:2 1 I 2225.

25. Dolbec J, Mergler D, Souza Passos CJ and Sousa de Moraes SL: Methylmercury exposure affects motor performance in riverine population of the Tapajos river, Brazilian Amazon Int Arch Occup Environ Health 2000, 73: 195-203.

26. Lebel J, Mergler D, Lucotte M, Amorim M, Dolbec J, Miranda D, Arantes $G$, Rheault I and Pichet $P$ : Evidence of early nervous system dysfunction in Amazonian populations exposed to low levels of methylmercury Neurotoxicology 1996, 17:157-68.

27. Yokoo EM, Valente JG, Sichieri R and Silva EC: Validation and calibration of mercury exposure in riverine population in Pantanal Mato-Grossense, Brazil Environ Res 200I, 86:88-93.

28. Boischio AA and Henschel DS: Risk assessment of mercury exposure through fish consumption by the riverside people in the Madeira Basin, Amazon, 1991 Neurotoxicology 1996, 17:169-76.

29. Hacon S, Rochedo ERR, Campos RRR and Lacerda LD: Mercury exposure through fish consumption in the urban area of Alta Floresta in the Amazon Basin Journal of Geochemical Exploration 1997, 58:209-16.

30. Lebel J, Roulet M, Mergler D, Lucotte M and Larribe F: Fish diet and mercury exposure in a riparian Amazonian population Water Air Soil Pollut 1997, 97:31-44.

31. Kehrig HA, Malm O, Akagi H, Guimaraes JRD and Torres JPM: Methylmercury in fish and hair samples from Balbina Reservoir, Brazilian Amazon Environ Res 1998, 77(section A):84-90.

32. Hylander LD, Meili M, Oliveira LJ, de Castro eSilva E, Guimaraes JR, Araujo DM, Neves RP, Stachiw R, Barros AJ and Silva GD: Relationship of mercury with aluminum, iron and manganese oxyhydroxides in sediments from the Alto Pantanal, Brazil Sci Total Environ 2000, 260:97-107.

33. Câmara V, Silva AP and Piveta F: Estudo dos níveis de exposição e efeitos à saúde por mercúrio metálico em uma população urbana de Poconé-MT Cadernos de Saúde Pública 1996, I 2:69-77.

34. Santa Rosa R, Muller RC, Alves CN, Sarkis JE, Bentes MH, Brabo E and de Oliveira ES: Determination of total mercury in workers' urine in gold shops of Itaituba, Para State, Brazil Sci Total Environ 2000, 26:169-76.

35. Spinelli MA, da Silva RR, Albuquerque MC, Yokoo EM and Guimaraes LV: Nutritional status indicators in the Polonoroeste area. I. Methodologic aspects and socioeconomic characteristics Rev Inst Med Trop Sao Paulo 1988, 30:169-73.

36. da Silva RR, Spinelli MA, Albuquerque MC, Dos Santos SM and Yokoo EM: Nutritional status indicators in the Polonoroeste area. IV. Diet surveys in families in six cities of the Polonoroeste area, Mato Grosso, Brazil, 1983 Rev Inst Med Trop Sao Paulo 1988, 30:|85-|19|.

37. Grandjean P, Budtz-Jorgensen E, White RF, Jorgensen PJ, Weihe P, Debes $F$ and Keiding N: Methylmercury exposure biomarkers as indicators of neurotoxicity in children aged 7 years $\mathrm{Am} J$ Epidemiol 1999, 149:301-5.

38. Resolucao da Secretaria de Estado de Saude 307 de I 4/08/9 I Publicada no Diario Oficial do Estado de Sao Paulo, secao I, 15/08/9I

39. Johnson BL: Recommended neurobehavioral test methods In: Prevention of neurotoxic illness in working populations: a textbook of neurotoxic illness Edited by: Johnson B. New York: John Wiley; 1987:169-209.

40. Wechsler D: Wechsler Memory Scale Manual San Antonio, TX, The Psychological Corporation 1974.

41. Wechsler D: WAIS Manual New York, The Psychological Corporation 1955.

42. CEPA (Centro de Psicologia Aplicada): Aptidao mecanica - TAM. In: Manual de psicologia aplicada 24.17 CEPA, Rio de Janeiro 1994

43. CEPA (Centro de Psicologia Aplicada): Bateria CEPA - testes de aptidoes especificas. In: Manual de psicologia aplicada 24.17 CEPA, Rio de Janeiro 1994.

44. Feldman RG: Mercury In: Occupational and Environmental Neurotoxicology Edited by: Feldman RG. Philadelphia, Lippincott - Raven; 1998:92II5.

45. Spinelli MA, da Silva RR, Albuquerque MC and Yokoo EM: Nutritional status indicators in the Polonoroeste area. VI. Anthropometric study, 1985 Rev Inst Med Top Sao Paulo 1988, 30:197-201.

46. Kandel E, Schwartz JH and Jessell T: Principles of Neural Science Norwalk, CT: Appleton and Lange 2000.
47. Zavariz $C$ and Glina MR: Neuropsychological clinical assessment of workers in an electric lamp factory exposed to metallic mercury Rev Saude Publ 1992, 26:356-65.

48. Needleman HL and Gatsonis GA: Low-level lead exposure and the IQ of children: a meta-analysis of modern studies JAMA 1990, 263:673-8.

49. Rice $D$ and Batrone S: Critical periods of vulnerability for the developing nervous system: evidence from humans and animal models Environ Health Perspect 2000, 108:5 I I-533.

\section{Pre-publication history}

The pre-publication history for this paper can be accessed here:

http://www.biomedcentral.com/content/backmatter/ 1476-069x-2-8-b1.pdf

Publish with Bio Med Central and every scientist can read your work free of charge

"BioMed Central will be the most significant development for disseminating the results of biomedical research in our lifetime. "

Sir Paul Nurse, Cancer Research UK

Your research papers will be:

- available free of charge to the entire biomedical community

- peer reviewed and published immediately upon acceptance

- cited in PubMed and archived on PubMed Central

- yours - you keep the copyright

Submit your manuscript here:

http://www.biomedcentral.com/info/publishing_adv.asp
BiolMedcentral 